\title{
Optimization using Adjusted Program Budget Marginal-Analysis (PBMA) for Decision Making Process and Budget Planning Purposes
}

\author{
Bilkisu Maijamaa
}

\author{
Nasarawa State University, Keffi \\ maijamaab@nsuk.edu.ng
}

\begin{tabular}{ll}
\hline \multicolumn{2}{l}{ ARTICLE DETAILS } \\
\hline History & \\
Received $\quad$ February \\
Revised Format $:$ March \\
Accepted : April \\
\hline
\end{tabular}

Keywords : PBMA, Optimization, budget allocation.

\begin{abstract}
S
Program budget marginal-analysis is a framework used by decision makers to allocate and reallocate resources with maximized benefit or specified goals. Evidently most application of PBMA as employed in most studies have focused mainly within the health organization. To implement the PBMA for optimizing budget allocation problems it involves seven stages. This research will look at applying the PBMA in other organizations that are strategically based for budget allocations. To implement on other organizations, some adjustment on the existing PBMA need to be made. This was achieved through introduction of suitable quantitative approach instead of using the traditional qualitative approach to calculate the marginal cost for the activities/strategies. By introducing and implementation of a suitable mathematical programming model for the final budget allocation process. The adjusted PBMA has proven to be a flexible and workable framework that can be used in other organization not just the health sector where it originated. Hence it is recommended to be used by other organizations for optimal budget allocations.
\end{abstract}

\section{INTRODUCTION}

Program budget marginal-analysis (PBMA) seems to be one possible way of improving the allocation of budget by reviewing the effectiveness or the efficiency of the existing strategies and the new suggested strategies.To implement PBMA for optimizing budget allocation problem, some adjustments on the existing PBMA must be made. To recall, the steps for PBMA as stated by Mitton (2013) are as follows:

i. Determine the goal, aim and scope of setting the program.

ii. Identify the available resources for funding a particular program, which is the program budget.

iii. Conduct marginal analysis by taking the viewpoints of stakeholders, managers, service providers, consumers, and head of organizations in setting priorities.

iv. Determine the decision-making criteria to be used to maximize benefits or profits as well as minimization of cost.

v. Identify the options in the program for which choices are to be made. These can be achieved through the process of MCDA.

vi. Evaluate the potential impact of investment and disinvestment regarding benefit and cost.

vii. Validate the outcome and the decision made in the process of allocation and reallocation of funds according to the ratio of cost-benefit.

There are two major steps from the existing PBMA-steps that can be improved. The first major step is on the steps on conducting the marginal analysis by taking the viewpoints of stakeholders, managers, service providers, consumers, and head of organizations in setting priorities (Maijama'a, B., \& Nazrib, E. M. (2018); Aziz, R. W. A., Shuib, A., Nawawi, A. H., 
\& Tawil, N. M. (2015)).. The existing implementation is solely based on perceptions and preferences of those parties involved. This, to a certain extent can certainly lead to biased and inaccurate preferences and evaluations. As such, the marginal analysis should be conducted and formulated using some deterministic, evidence-based approaches to reduce the biasness.

The second concern is on the identification of the options in the program for which choices are to be made which currently is achieved through the application of a certain MCDA approach. In other words, the allocation of budget to strategies and activities is based on subjective evaluation by the decision makers based on the decision makers' preference weight and ranking or based on expert opinion (AL-Khalek, A. M. M. A. 2014). . This once again may lead to biased budget allocation. In addition, it will be difficult to prove that the allocation is just and accurate without showing a concrete evidence. Thus, it is suggested that some form of deterministic mathematical model to be utilized for this budget allocation process.

Unfortunately, not many studies have been able to identify any systematic concept into applying the PBMA on other organizations. This is evidently so, since the application of PBMA as employed in most of the studies have focused mainly within health organizations. Thus, presenting the need for the adaptation of the method to make it suitable for other organizations whose focus is towards service-delivery is seen to be very timely. This is essentially required considering the financial constraints faced by so many organizations and the corresponding need to enhance performance of these organizations.

The underpinning objective of this study is to propose an adjusted-PBMA that can be applied by many organisations is to solve their budgetary problem in the allocation of funds to activities aimed at achieving the optimal performance.

The adjusted PBMA will used MCDA, this can be subjective, as the deterring factor. under the adjusted-PBMA approach, the study shall propose the use of any objectively and quantitatively suitable marginal cost as one of the determining factors.

the adjusted-PBMA we proposed the use of IP-model for the budget distribution. IP-model can not only distribute the budget allocated among strategies if the budget allocation is already determined ahead of time and is fixed, but the IP-model can also determine the proper budget to be reserved if a certain target or KPIs need to be attained.

MCDA approach comprises of a range of procedures and techniques developed in many areas of decision making through making decisions on complex problems with an explicit, transparent, and consistent way used mostly to compliment priority settings such as the PBMA (Smith et al. 2016; Sullivan, 2012). It involves identifying programs that need priority, deciding who should be given priority and determining the importance of the criteria, while ensuring consistency and transparency in the process (Sullivan, 2012). Golan et al. (2011) for example, in their review on application of health technology involving the selection of appropriate technology to be applied in different countries, the criteria used for prioritization are as given below (Source: Golan et al. (2011) health technology prioritization HTP).

Criteria for Prioritization

- Need for appropriateness and benefits.

- Efficiency.

- Solidarity, social equality and ethical values.

- Consistent with allocative justice principles.

In addressing multi-criteria problems, the concept of the optimal solution is not the goal. Instead, the goal is helping the decision maker to bring a clear solution to the problem through advancing towards a solution which is mostly a compromise. This process depends on not only different factors such as organizational and decision makers but also on circumstances that are prevailing and hence the different methods used for MCDA also address the problem with conflicting, multiple incommensurable criteria. Resolving these problems does not mean finding the final truth rather it helps the decision maker to address the complex situation through handling the data to make advancement towards getting a solution (Omann, 2004). 
Multi-Criteria Decision-Analysis (MCDA) investigates methods that are discrete and has relations that are outranking, that is comparing options through evaluation to decide on which option is better than the other based on the criteria employed. It involves a process to promote transparency with the goal of arriving at a satisfactory solution.

\section{METHODOLOGY}

The methodology employed will start with the description of the proposed adjustedPBMA and ends with the flowchart for adjusted-PBMA. First step is Identifying the research gap which involves the aspects of the existing PBMA that can be improved. Second step is developing the adjusted-PBMA framework.

The Existing PBMA and Changes to be Made Under Adjusted-PBMA

To develop the adjusted-PBMA the first two steps under PBMA were maintained. Step 3 and step 4 under PBMA were combined into one step. The other three steps, step 5, step 6, and step 7 were modified slightly. The modifications made are as listed in Table 3.1.

Table 3.1 PBMA and Proposed-Changes Under Adjusted-PBMA Steps.

\begin{tabular}{lll}
\hline PBMA Steps & Adjusted-PBMA Steps \\
\hline 1 & $\begin{array}{l}\text { Determining the goal, aim and } 1 \text { Maintain } \\
\text { scope of setting the program. }\end{array}$ \\
\hline 2 & $\begin{array}{l}\text { Identifying the available } 2 \text { Maintain } \\
\text { resources for funding a particular } \\
\text { program, that is the program } \\
\text { budget. }\end{array}$
\end{tabular}

3 Conducting marginal analysis by 3 Calculating the marginal analysis for the taking the viewpoints of strategies/activities using a quantitative formula as stakeholders, managers, service providers, consumers, and head of organizations in setting priorities. the measure of marginal contribution of each strategy/activity towards the final goal. In this thesis, the marginal cost of running/executing an activity/strategy and CCA to calculate the contribution of each activity's achievement with respect to the needed points were applied.

4 Determining the decision-making criteria to be used to maximize benefits or profits as well as minimization of cost.

5 Identifying the options in the 4 Determining the decision-making criteria to be program for which choices are to be made. These can be achieved through the process of MCDA.

6 Evaluating the potential impact of investment and disinvestment regarding benefit and cost. used to maximize benefits or profits as well as minimization of cost and introducing new strategies. In this thesis, the decision-making criterion used was the needed points.

5 Evaluating the potential impact of investment and disinvestment regarding benefits and cost. This can be achieved by developing suitable mathematical model to identify which set of old strategies/activities that should remain and which set of the newly proposed strategies/activities that should be implemented.

7 Validating the outcome and the 6 Validating of the proposed models with suitable decision made in the process of allocation and re-allocation of validation techniques and conducting what-if analysis. funds according to the ratio of cost-benefit. 
The major changes in the adjusted PBMA is ----- which will be the formulation of linear programming models to be used to determine the total budget needed to achieve $90 \%$ needed marks for all existing strategies and the second model will be to maximize the total needed points which can be obtained given a specific budget allocation by an organization.

First Model: To Determine the Total Budget that must be Set Aside to Achieve 90 percent needed Marks for all the Strategies Involved.

Objective function:

Minimize Total Budget Required $=\sum_{i=1}^{I} c_{i} X_{i}$

Subject to

Constraint 1: Total points to be accumulated for each activity or person

$$
P_{i} X_{i} \leq \text { Point }_{i} \text { For each } \mathrm{i}=1,2,3, \ldots, I
$$

Constraint 2: Total needed points for all the activities

$\mathrm{Xi} \geq 0$ and integer.

$$
\sum_{i=1}^{I} P_{i} X_{i} \geq 95 \% \text { SET ARA Point }
$$

Where

$c_{i}=$ marginal cost for strategy/activity $i$

$P_{i}=$ expected points that can be accumulated by each strategy/activity $i$

Point $_{i}=$ total needed points to be accumulated for each strategy/activity $i$

Second Model : To Maximize Total needed Points That can be Obtained Given the Amount of Budget Allocated by the organization, for the Existing Strategies.

Objective function:

Maximize total points that can be accumulated $=\sum_{i=1}^{I} P_{i} X_{i}$

Subject to

Constraint 1: Total points to be accumulated for each activity/strategy

$$
P_{i} X_{i} \leq \text { Point }_{i} \text { for each } \mathrm{i}=1,2,3, \ldots, I
$$

Constraint 2: Total budget allocated by the university management

$X_{i} \geq 0$ and integer

$$
\sum_{i=1}^{I} c_{i} X_{i} \leq \text { Total budget allocated }
$$

Where

$c_{i}=$ marginal cost for strategy/activity $i$

$P_{i}=$ expected points that can be accumulated by each strategy/activity $i$

Point $_{i}=$ total needed points to be accumulated for each strategy/activity $i$

\section{RESULTS}

To illustrate how the adjusted-PBMA can be implemented, a case study involving the budget allocation for student development agenda for the 2017 strategic plan at a university was conducted. Beginning with the illustration of each adjusted-PBMA steps, followed by the presentation of the results and the analysis of the results.

The Application of Adjusted-PBMA

As mentioned in the methodology, the adjusted-PBMA process involved six steps. Each step is explicitly illustrated here, starting with Step 1.

STEP 1: Determining the Goal, Aim and Scope of Setting the Program

The objective is to determine the strategies/activities that should include in the years Strategic Plan and to determine the total budget required for those strategies/activities to be implemented. Step 2: Identifying the Strategies Used for the Strategic Activities for the purpose of Rating. 
For the purpose of identifying the strategies/activities to be implemented for the year, the strategies/activities implemented in the previous year should be examined.

Step 3: Calculating the Marginal Cost of Each Strategy

As stated in the methodology, before the marginal cost could be calculated, firstly, the actual cost of conducting each activity/strategy for the previous year must be identified. At the same time, the actual achievement with respect to each activity/strategy for the previous year must also be identified as well.

Step 4: Determining the Decision-Making Criteria to be used to Maximize Benefits or Profits as Well as Minimization of Cost.

The criteria used in our decision-making model was based on CCA-value as shown below, CCA-value for strategy/activity $i=($ Expected SETARA point for strategy/activity $i /$ Expected SETARA output for strategy/activity $i$ ).

Step 5: Evaluating the Potential Impact of Investment and Disinvestment Regarding Benefits and Cost.

To evaluate the effect of introducing CCA and marginal cost in the decision-making process on the activities/strategies that should be undertaken, first and second linear programming models were constructed for the strategic plans. The models will involve only the existing activities/strategies implemented in the previous year. Here, we assumed that the cost of running each activity/strategy (marginal cost) and the CCA-values for previous year remained the same for this year. The two models are developed based on different objectives are as follows:

i. First Model: To minimize the total budget that must set aside to achieve 90 percent marks for all the existing

ii. Second model: To maximize total points that can be accumulated by given the amount of budget allocated by the organization, for the existing strategies.

Meanwhile, the decision variables used in the models are:

$X_{l}=$ total students development Outreach Programs.

$X_{2}=$ number of full-time students to be given scholarship yearly.

$X_{3}=$ number students involved in outbound programs in local universities with transfer of credit.

$X_{4}=$ number of students involved in outbound programs in international universities with credit transfer.

$X_{5}=$ number of promotional activities to attract international students.

$X_{6}=$ number of new academic staff with industrial experience to be hired.

$X_{7}=$ number of new academic staff with teaching experience abroad to be hired.

$X_{8}=$ number of academic staff to be sent for $\mathrm{PhD}$ or are currently doing their $\mathrm{PhD}$.

$X_{9}=$ number of new academic staff to be hired.

$X_{10}=$ number of staff sent for training.

The Parameters to be sed in the first and second Models.

KPI, 1, 2, 3, 4, 5, 6, 7, 8, 9, 10

Variable, $X_{1}, X_{2}, X_{3}, X_{4}, X_{5}, X_{6}, X_{7}, X_{8}, X_{9}, X_{10}$

Marginal Cost, 300, 6,000, 1,000, 3,000, 20,000, 96,000, 96,000, 125,000, 96,000, 500

CCA-Value, 0.004, 0.00029, 0.0007, 0.0007, 0.0028, 0.0033, 0.0025, 0.0007, 0.003, 0.0004

Required points , $0.6,0.2625,0.3,0.3,0.078,0,0.0825,0.06,0.308,0.2$

The first and second models were formulated, and the optimal result obtained for each model is given immediately after each model.

First Model. To minimize the total budget that must set aside to achieve 90 percent needed marks for all the existing strategies involved. 
Objective function: To minimize the total budget that must set aside to achieve 90 percent needed marks for all the existing strategies involved.

$\operatorname{Min} f(X)=300 X_{1}+6,000 X_{2}+1,000 X_{3}+3,000 X_{4}+20,000 X_{5}+96,000 X_{6}+96,000 X_{7}+125,000 X_{8}$ $+96,000 X_{9}+500 X_{10}$

Subject to these constraints:

i. Total points that can be garnered through student's development outreach programs. $0.004 X_{1} \leq 0.600$

ii. Total points that can be garnered through full- time UG students who receive scholarship yearly. $0.00029 X_{2} \leq 0.2625$

iii. Total points that can be garnered through outbound UG students to local universities with the transfer of credit. $0.0007 X_{3} \leq 0.300$

iv. Total points that can be garnered through outbound UG students to international universities with the transfer of credit. $0.0007 X_{4} \leq 0.300$

v. Total points that can be garnered through UG international students. $0.0028 X_{5} \leq 0.078$

vi. Total points that can be garnered through academic staff with industrial training. $0.0033 X_{6} \leq 0$

vii. Total points that can be garnered through academic staff with teaching experience abroad. $0.0025 X_{7} \leq 0.0825$

viii. Total points that can be garnered through academic staff with $\mathrm{PhD}$. $0.0007 X_{8} \leq 0.06$

ix. Total points that can be garnered through academic staff. $0.003 X_{9} \leq 0.308$

x. Total points that can be garnered through staff sent for training. $0.0004 X_{10} \leq 0.2$

xi. 90 percent of the total points to be garnered through the combination of all the strategies/activities [i.e. $0.90(0.6+0.263+0.3+0.3+0.013+0+0.275+0.06+0.308$ $+0.2)=0.90(2.319)=2.087]$.

$0.004 X_{2}+0.00029 X_{2}+0.0007 X_{3}+0.0007 X_{4}+0.0028 X_{5}+0.0033 X_{6}+0.0025 X_{7}+$ $0.0007 X_{8}+0.003 X_{9}+0.0004 X_{10} \geq 2.087$

$X_{i} \geq 0$ and integer, $i=1,2,3, \ldots, 10$.

Table 4.2 gives the optimal result for the first Model (please refer to Appendix).

Table 4.2 Optimal result for first Model.

\begin{tabular}{cl}
\hline Variable & \multicolumn{1}{c}{ Solution } \\
\hline $\boldsymbol{X}_{1}$ & 150 student's development outreach programs. \\
\hline $\boldsymbol{X}_{2}$ & 875 full- time UG students to be given scholarship yearly. \\
\hline $\boldsymbol{X}_{3}$ & $\begin{array}{l}\text { 428 UG students to be sent to local universities for outbound } \\
\text { program with the transfer of credit. }\end{array}$ \\
\hline $\boldsymbol{X}_{4}$ & $\begin{array}{l}428 \text { UG students to be sent to international universities for } \\
\text { outbound program with the transfer of credit. }\end{array}$ \\
\hline $\boldsymbol{X}_{5}$ & 27 promotional programs. \\
\hline $\boldsymbol{X}_{6}$ & 0 academic staff with industrial training to be hired. \\
\hline $\boldsymbol{X}_{7}$ & $\begin{array}{l}21 \text { academic staff with teaching experience abroad to be hired or to } \\
\text { be sent for teaching assignment abroad. }\end{array}$ \\
\hline $\boldsymbol{X}_{8}$ & $\begin{array}{l}\text { 0 academic staff with PhD to be hired or existing staff to be sent } \\
\text { for PhD. }\end{array}$ \\
\hline$X_{9}$ & 102 new academic staff to be hired. \\
\hline
\end{tabular}




\begin{tabular}{ll}
\hline$X_{10}$ & 500 staff sent for training. \\
\hline Total Budget & RM 19,605,200 \\
\hline
\end{tabular}

\section{Second Model.}

Objective function: To maximize total points that can be accumulated by given the amount of budget allocated by the organization, for the existing strategies. For this purpose, we assumed that the total budget allocated by is $25,000,000$.

$\operatorname{Max} f(X)=0.004 X_{2}+0.00029 X_{2}+0.0007 X_{3}+0.0007 X_{4}+0.0028 X_{5}+0.0033 X_{6}+0.0025 X_{7}+$ $0.0007 X_{8}+0.003 X_{9}+0.0004 X_{10}$

Subject to these constraints:

i. Total points that can be garnered through student's development outreach programs.

$$
0.004 X_{1} \leq 0.600
$$

ii. Total points that can be garnered through full- time UG students who receive scholarship yearly. $0.00029 X_{2} \leq 0.263$

iii. Total points that can be garnered through outbound UG students to local universities with the transfer of credit. $0.0007 X_{3} \leq 0.300$

iv. Total points that can be garnered through outbound UG students to international universities with the transfer of credit. $0.0007 X_{4} \leq 0.300$

v. Total points that can be garnered through UG international students. $0.0028 X_{5} \leq 0.013$

vi. Total points that can be garnered through academic staff with industrial training. $0.0033 X_{6} \leq 0$

vii. Total points that can be garnered through academic staff with teaching experience abroad.

$$
0.0025 X_{7} \leq 0.0825
$$

viii. Total points that can be garnered through academic staff with $\mathrm{PhD}$. $0.0007 X_{8} \leq 0.06$

ix. Total points that can be garnered through academic staff. $0.003 X_{9} \leq 0.308$

x. Total points that can be garnered through staff sent for training. $0.0004 X_{10} \leq 0.2$

xi. Total budget allocated by.

xii. $\quad 300 X_{1}+6,000 X_{2}+1,000 X_{3}+3,000 X_{4}+20,000 X_{5}+96,000 X_{6}+96,000 X_{7}+125,000 X_{8}+$ $96,000 X_{9}+500 X_{10} \leq 25,000,000$

$X_{i} \geq 0$ and integer, $i=1,2,3, \ldots, 10$.

The optimal result is as shown in Table 4.3. Please refer to Appendix for the Lingo 12.0 output.

Table 4.3 Optimal result for second Model..

\begin{tabular}{ll}
\hline Variable & Solution \\
\hline $\boldsymbol{X}_{\boldsymbol{I}}$ & 150 student's development outreach programs. \\
\hline $\boldsymbol{X}_{2}$ & 876 full- time UG students to be given scholarship yearly. \\
\hline $\boldsymbol{X}_{3}$ & $\begin{array}{l}\text { 428 UG students to be sent to local universities for outbound } \\
\text { program with the transfer of credit. }\end{array}$ \\
\hline $\boldsymbol{X}_{4}$ & $\begin{array}{l}\text { 428 UG students to be sent to international universities for } \\
\text { outbound program with the transfer of credit. }\end{array}$ \\
\hline $\boldsymbol{X}_{5}$ & 27 promotional programs. \\
\hline $\boldsymbol{X}_{6}$ & 0 academic staff with industrial training to be hired. \\
\hline $\boldsymbol{X}_{7}$ & $\begin{array}{l}33 \text { academic staff with teaching experience abroad to be hired } \\
\text { or to be sent for teaching assignment abroad. }\end{array}$ \\
\hline
\end{tabular}




\begin{tabular}{ll}
\hline $\boldsymbol{X}_{\boldsymbol{\delta}}$ & $\begin{array}{l}33 \text { academic staff with } \mathrm{PhD} \text { to be hired or existing staff to be } \\
\text { sent for } \mathrm{PhD} .\end{array}$ \\
\hline $\boldsymbol{X}_{\boldsymbol{9}}$ & 102 new academic staff to be hired. \\
\hline $\boldsymbol{X}_{\boldsymbol{1 0}}$ & 500 staff sent for training. \\
\hline Total points obtained & $2.14(92.28$ percent $)$ \\
\hline
\end{tabular}

\section{SUMMARY CONCLUSION AND RECOMMENDATION}

This research focused on the efficient budget allocation for optimal performance through adjusted-PBMA aimed at optimizing the choice of strategies/activities to improve needed rating. The main

Firstly, objective which is to adjust the existing PBMA was achieved by introducing the use of a suitable quantitative approach instead of using a qualitative approach to calculate the marginal cost for the activities/strategies, and by introducing the implementation of a suitable mathematical programming model for the final budget allocation process.

\section{CONCLUSIONS}

The implications of the proposed adjusted-PBMA for the theory in Decision Science are three-folds. Firstly, the presentation of PBMA proposed the use of MCDA, which can be very subjective, as the determining factor in the budget-planning decision problem. However, under the adjusted-PBMA approach, we proposed the use of any objectively and quantitatively suitable marginal cost formula as the determining factor.

Implications for Practice for study has shown how PBMA framework that is currently being used by healthcare institutions for the budget-planning exercise could also be used in other KPI-based service-oriented institutions with slight modifications.

\section{LIMITATIONS OF THE STUDY AND SUGGESTIONS FOR FUTURE RESEARCH}

In general, adjusted-PBMA has proven to be flexible framework that can be used in other organizations not just in the health sector where it originated, but also in other organizations especially the strategically-based service organizations as mentioned earlier and as shown in this study to be workable. The linear Programming model proposed may not work if the relationship among variables are not linear. Furthermore, the IP-model is not able to generate an optimal solution, in which some other techniques such as goal programming need to be utilized.

\section{RECOMMENDATIONS}

Based on the results of this research, a few recommendations are proposed. Firstly, it is recommended that the model should not be conducted by examining each agendum separately. All the strategic agenda should be included in the entire model because some of the activities can fulfil more than one agendum.

The second recommendation will be on the selection and determination of strategies and activities. In reality, when selecting and determining the strategies and activities, other factors such as the preference or perhaps the capability of the management staff in executing the strategies and activities should also be taken into consideration. Thus, for future work, this research suggests for this preference and capability factors to be included in the model. 


\section{REFERENCES}

AL-Khalek, A. M. M. A. (2014). Technique For Organizations (Doctoral dissertation) Fayoum University, Egypt.

Aziz, R. W. A., Shuib, A., Nawawi, A. H., \& Tawil, N. M. (2015). Mathematical model for budget planning and execution. Journal of Industrial and Intelligent Information, 3(2), 2315-4462. doi: 10.12720/jiii.3.2.91-96.

Dantzig, G. (2016). Linear programming and extensions. New Jersey: Princeton university press.

Golan, O., Hansen, P., Kaplan, G., \& Tal, O. (2011). Health technology prioritization: which criteria for prioritizing new technologies and what are their relative weights?Health Policy, 102(2),126-135. doi: 10.1016/j.healthpol.2010.10.012.

Maijama'a, B., Adehi, M. U., \& Abdullahi, I. O. (2017) A Conceptual Paper on Program-Budget Marginal Analysis for Optimal Performance of a University.

Maijama'a, B., \& Nazrib, E. M. (2018). Program-Budget Marginal-Analysis for University Strategies concept of Planning and Execution. Asian Journal of Multidisciplinary Studies, 6(6), 79-83.

Mitton, C., Dionne, F., \& Donaldson, C. (2014). Managing Healthcare Budgets in Times of Austerity: The Role of Program Budgeting and Marginal Analysis. Applied health economics and health policy, 12(2), 95-102. doi: 10.1007/s40258-013-0074-5.

Omann, I. (2004). Multi-criteria decision aid as an approach for sustainable development analysis and implementation: United State USA:na, publishers.

Smith, N., Mitton, C., Dowling, L., Hiltz, M.-A., Campbell, M., \& Gujar, S. A. (2016). Introducing new priority setting and resource allocation processes in a Canadian healthcare organization: a case study analysis informed by multiple streams theory. International Journal of Health Policy and Management, 5(1), 23. doi: $10.15171 /$ ijhpm.2015.169.

Sullivan, T. (2012). Using MCDA (Multi-Criteria Decision Analysis) to prioritise publiclyfunded health care(Doctoral Dissertation) University of Otago, New Zealand. Retrieved from http://hdl.handle.net/10523/2651. 